\title{
A formação humana na perspectiva histórico-ontológica*
}

\author{
Dermeval Saviani \\ Universidade Estadual de Campinas, Faculdade de Educação
}

Newton Duarte

Universidade Estadual Paulista, campus de Araraquara, Faculdade de Ciências e Letras

\section{O sentido da filosofia da educação e a formação humana}

Pode-se considerar consensual a definição da educação como formação humana. A questão, portanto, que necessita ser examinada é em que consiste a formação humana. Admitindo que determinados homens, as crianças e os jovens são formados por outros homens, os adultos, cabe verificar se isso é possível e, em caso positivo, se é legítimo. Estamos aí diante de uma questão filosófica por excelência, ligada ao problema da possibilidade, da legitimidade, do valor e dos limites das ações humanas.

No livro Educação brasileira: estrutura e sistema (Saviani, 2008a), cuja primeira edição data de 1973, empreendeu-se a análise da estrutura do homem visando exatamente resolver os problemas da possibilidade, da legitimidade, do valor e dos limites da educação, à semelhança do que fizera Kant com a questão do conhecimento.

* Trabalho encomendado pelo Grupo de Trabalho Filosofia da Educação, apresentado na $32^{\mathrm{a}}$ Reunião da ANPEd, realizada de 4 a 7 de outubro de 2009 em Caxambu-MG.
A educação revelava-se impossível na medida em que fossem considerados apenas os elementos que caracterizam a estrutura do homem em seu aspecto empírico. Ou seja: enquanto ser situado, determinado pelas condições do meio natural e cultural, a educação resultava impossível.

No entanto, a análise do aspecto pessoal, isto é, da liberdade, mostrava o homem como um ser que, embora situado, se revelava capaz de intervir pessoalmente na situação para aceitar, rejeitar ou transformar. Enquanto ser livre, ele mostrava-se capaz de optar e tomar decisões. Esse aspecto já permitia responder positivamente à questão da possibilidade da educação. Se o homem é livre e capaz de intervir na situação, então ele pode intervir na vida das novas gerações para educá-las. Mas ficava sem solução o problema da legitimidade da educação: com que direito o educador vai interferir na vida do educando se este, como ele, é igualmente livre porque também pertencente ao gênero humano?

A análise do aspecto intelectual, isto é, da consciência, revela que o homem não se mantém preso às suas condições situacionais e pessoais. Ele é capaz de transcender a situação, assim como as opções e os 
pontos de vista pessoais, para colocar-se na perspectiva universal, entrando em comunicação com os outros e reconhecendo suas condições situacionais, assim como suas opções e seus próprios pontos de vista. Funda-se, aí, a legitimidade da educação, que emerge, então, como uma comunicação entre pessoas livres em graus diferentes de maturação humana. Nessa formulação, o valor da educação expressa-se como promoção do homem. Enunciamos, então, uma primeira definição de educação: a educação, enquanto comunicação entre pessoas livres em graus diferentes de maturação humana, é promoção do homem, de parte a parte - isto é, tanto do educando como do educador.

A formação humana coincide, nessa acepção, com o processo de promoção humana levado a efeito pela educação. Dessa forma, a filosofia da educação cumpre um papel preliminar de estabelecer a própria identidade de seu objeto, isto é, a educação.

Determinado o objeto, entre as várias funções da filosofia da educação, tais como o esclarecimento das formas de abordagem, a referência aos clássicos, a diferenciação das concepções pedagógicas e a clareza conceitual e terminológica, destaca-se a vigilância crítica. Esta atribui à filosofia da educação a tarefa precípua de acompanhar reflexiva e criticamente a atividade educacional, de modo que explicite os seus fundamentos, esclareça a contribuição das diversas disciplinas pedagógicas e avalie o significado das soluções escolhidas.

\section{A filosofia da educação, a formação humana e a situação atual}

Se admitirmos que a tarefa de vigilância crítica da filosofia da educação corresponde ao seu caráter de uma reflexão radical, rigorosa e de conjunto sobre os problemas que a realidade apresenta, cumpre voltarmos os olhos para a realidade atual para vermos qual é sua nota distintiva.

Como se caracteriza a situação atual? Constatamos que é mais ou menos recorrente o entendimento de que a situação atual é caracterizada, de forma genérica, pela crise de paradigmas.
Ora, é também recorrente a ideia de que as situações de crise são épocas propícias para a filosofia, já que nos obrigam a compreender as raízes da crise e pensar alternativas à sua superação.

Mas, independentemente das crises, parece mais ou menos evidente a importância da filosofia para a formação do homem e, consequentemente, também para a formação do educador.

Com efeito, se a educação é uma atividade específica dos seres humanos, se ela coincide com o processo de formação humana, isso significa que o educador digno desse nome deverá ser um profundo conhecedor do homem.

E a filosofia é a forma mais elaborada do grau mais elevado de compreensão do homem atingido pelo próprio homem. Gramsci (1978, p. 34-35) dizia que a filosofia é uma especialidade que interessa a todos os homens. Enquanto as especialidades, de modo geral veja-se o exemplo da entomologia -, interessa a uma pequena parcela de homens, a filosofia trata daquilo que é a qualidade humana por excelência, isto é, o pensamento, razão pela qual ela interessa a todos os homens. Por isso ele entendia que "todos os homens são filósofos", porque todos pensam, elaboram os próprios pensamentos e expressam a compreensão que têm de si mesmos e das coisas. Esclarecia, entretanto, que, se todos os homens são filósofos, nem todos exercem, na sociedade, a função de filosofar. Daí, então, os especialistas em filosofia, que, contudo, se dedicam a uma especialidade que interessa não apenas a poucos homens, mas a todos, à humanidade em seu conjunto.

Mas o conteúdo da filosofia é a história, isto é, a produção da própria existência humana no tempo. Assim, podemos concluir que a filosofia e a história da educação constituem o núcleo duro da formação do educador.

Entretanto, se o conteúdo da filosofia é a história, o método de filosofar pode elidir a história ao fazer abstração de seu movimento concreto e convertê-la em ideias que se justificam por si mesmas, se movimentam de forma autônoma e, na sua formulação mais extrema, se convertem em geradoras do próprio 
mundo real. Esse modo de filosofar é conhecido pelo nome de metafísica.

O antídoto ao modo metafísico de filosofar é a historicização, isto é, a concepção que toma a história não apenas como o conteúdo da filosofia, mas também como o seu método, ou seja, que unifica na história o conteúdo e a forma da filosofia.

A partir dessas premissas podemos analisar a situação atual e a crise que a configura.

\section{Fenomenologia da época atual}

As ideias que hoje parecem ser hegemônicas se manifestam como expressão de crise na medida em que não se afirmam positivamente, mas expressam-se como negação daquilo que é denominado a "metafísica do sujeito", característica da modernidade.

Daí a crítica à razão, à consciência, às noções de verdade e de objetividade, a substituição da epistemologia pela linguística e da lógica pela semântica, chegando-se à conclusão de que não faz sentido se falar em conhecimento das coisas, já que tudo se resume a "jogos de linguagem". Mas afirmar que "tudo é linguagem" não é um enunciado metafísico? E, no entanto, isso é afirmado precisamente como forma de se contrapor exatamente à metafísica que teria caracterizado as concepções filosóficas anteriores, em especial aquela da modernidade.

Nesse contexto, o século XX parece um parêntesis histórico, uma espécie de sonho (para os socialistas) ou um pesadelo (para a burguesia) de que o capitalismo seria ultrapassado, cedendo lugar a uma sociedade socialista. Acordamos, no final desse século, os primeiros com a desilusão de que foi apenas um sonho e os segundos com o alívio de que tinha sido somente um pesadelo. E retomam-se as críticas à razão que haviam marcado as principais tendências filosóficas da passagem do século XIX para o século XX, como se este último século não tivesse existido.

Retomemos o fio da história para tentar dissipar essas falácias filosóficas.

A ideia de que a metafísica é algo que está além da física, entendido este "além" como algo que a ultra- passa porque a precede e a fundamenta, deriva de uma leitura de Aristóteles que não corresponde nem à forma como se desenvolveram os estudos desse filósofo, nem ao modo como foram dispostos os seus escritos. Com efeito, os estudos sobre a física precederam os da metafísica, cujo nome, por sua vez, deriva do fato de que, na organização da obra de Aristóteles, foram chamados de metafísicos aqueles que foram postos depois dos escritos sobre a física.

Ao mesmo tempo, sabemos também que foi a física aristotélica, de caráter ptolomaico, que esteve na base da sua metafísica. Tanto assim que, com a substituição da física ptolomaica pela física de Copérnico, no final da Idade Média, a metafísica aristotélica veio a ruir, o que colocou a necessidade de uma nova metafísica, de base copernicana. Essa foi a tarefa que se impôs Descartes, tendo-a formulado no Discurso do Método, obra que inaugura a filosofia moderna, e dando-lhe uma forma acabada nas Meditações sobre a filosofia primeira.

A metafísica dos tempos antigos e medievais, isto é, a metafísica aristotélica, era uma metafísica do objeto (ou objetivista). Em contrapartida, a metafísica da modernidade era uma metafísica do sujeito (ou subjetivista).

Entretanto, não procede a afirmação de que a metafísica é um pensamento substantivador, isto é, que atribui às suas ideias centrais o caráter de substância, ou seja, de uma coisa que se sustenta em si e por si. Esse entendimento tem levado a se considerar que a metafísica da modernidade, por ser uma metafísica do sujeito, consideraria o sujeito como uma substância, como algo que subsiste em si e por si.

$\mathrm{Na}$ verdade, a história da filosofia moderna pode ser lida como a história da erosão da noção de substância, isto é, como um processo que começou admitindo a ideia de substância, mas progressivamente a eliminou.

Com efeito, se a referida afirmação é válida para Descartes, para quem o sujeito era res cogitans, isto é, uma coisa pensante, e o objeto era uma res extensa, isto é, uma coisa material, ela é só parcialmente válida no caso de Berkeley, em cujo pensamento já não há lugar para as substâncias materiais, restando apenas a 
substância espiritual; e, finalmente, aquela afirmação já não tem nenhuma validade em relação a Kant, para quem a própria noção de sujeito transcendental já não tem nenhum caráter substantivo, reduzindo-se a uma mera função de conhecimento.

As ideias hoje hegemônicas, ao mesmo tempo em que situam o marxismo como um pensamento próprio da modernidade, portanto, marcado pela metafísica do sujeito, o criticam por ter se limitado a análises totalizantes, objetivantes, sociologizantes, não deixando espaço para os indivíduos, os sujeitos e os aspectos psicológicos.

É preciso, pois, restabelecer o entendimento de que o pensamento de Marx é caracteristicamente antimetafísico, manifestando-se provavelmente como a forma mais acabada de um modo de filosofar que unifica, na história, o conteúdo e a forma da filosofia. É, assim, uma filosofia ao mesmo tempo histórica e historicizadora em que estão em causa não os indivíduos ou sujeitos abstratos, mas os indivíduos reais, sujeitos históricos que se constituem como síntese de relações sociais.

Por isso, em face do neopragmatismo que hoje busca reabilitar o pragmatismo alçando-o, pela via da filosofia analítica, à condição de pensamento hegemônico, conviria retomar as teses de Marx sobre Feuerbach (Marx, s.d., p. 9-13).

Poderíamos dizer que a Tese 2 de Marx sobre Feuerbach tem pontos de contato com o pragmatismo quando afirma que

[...] o problema da possibilidade de atribuir ao pensamento humano uma verdade objetiva não é um problema teórico, mas sim um problema prático. É na prática que o homem deve demonstrar a verdade, ou seja, a realidade e o poder do seu pensamento. A controvérsia em torno da realidade ou irrealidade do pensamento - isolado da prática - é um problema puramente escolástico.

E isso é também reforçado pela Tese 8: "Toda a vida social é essencialmente prática. Todos os mistérios que desembocam na teoria do misticismo encontram solução racional na prática humana e na compreensão dessa prática".
Mas o limite do pragmatismo consiste em não tomar essa prática enquanto prática humana histórica, como está explicitado na Tese 6:

\begin{abstract}
Feuerbach dissolve a essência religiosa na essência humana.
Mas a essência humana não é uma abstração imanente ao indivíduo isolado. Na realidade, é o conjunto das relações sociais. Feuerbach, não entrando na crítica desta essência real, vê-se por isso obrigado: $1^{\circ}$ - a prescindir do processo histórico, considerando o sentimento religioso em si e pressupondo um indivíduo humano abstrato, isolado. $2^{\circ}$ - a essência só pode conceber-se, por conseguinte, de um modo "genérico", como uma generalidade interna, silenciosa, que una de um modo natural muitos indivíduos.
\end{abstract}

Poderíamos, pois, aplicar o conteúdo da Tese 7, "Feuerbach não vê, portanto, que o 'sentimento religioso’é, por sua vez, um produto social, e que o indivíduo abstrato por ele analisado pertence a uma determinada forma de sociedade", ao neopragmatismo, traduzida ou, para ficar em seu universo vocabular, redescrita nos seguintes termos: "O neopragmatismo não vê, portanto, que o comportamento dos indivíduos, em geral, e o 'comportamento linguístico', em particular, é, por sua vez, um produto social, e que o indivíduo falante abstrato por ele analisado pertence a uma determinada forma de sociedade".

Consequentemente, para compreender o modo de ser do homem, isto é, para entender como ele se forma historicamente, nada melhor do que um modo de filosofar que tenha a história como conteúdo e forma. E esse modo de filosofar, como já foi assinalado, atinge sua expressão mais elaborada com o marxismo. Cumpre, pois, retomar a contribuição de Marx na discussão do problema da formação do ser humano em sua manifestação histórica concreta na forma social capitalista.

\section{Perspectiva histórico-ontológica da formação humana}

A perspectiva histórico-ontológica da formação humana se faz presente ao longo de toda a obra de Karl Marx. Diante dos limites de espaço de um artigo, 
optamos por analisar a formação humana em um dos trabalhos desse autor, os Manuscritos econômicofilosóficos de 1844 (Marx, 1985), sem perder de vista as relações entre esse escrito juvenil de Marx e o restante de sua obra.

Nos Manuscritos, a formação humana é analisada na relação entre o processo histórico de objetivação do gênero humano e a vida do indivíduo como um ser social. O que faz do indivíduo um ser genérico, isto é, um representante do gênero humano, é a atividade vital, a qual é definida por Marx como aquela que assegura a vida de uma espécie. No caso dos seres humanos, sua atividade vital, que é o trabalho, distingue-se daquelas de outras espécies vivas por ser uma atividade consciente que se objetiva em produtos que passam a ter funções definidas pela prática social. Por meio do trabalho o ser humano incorpora, de forma historicamente universalizadora, a natureza ao campo dos fenômenos sociais. Nesse processo, as necessidades humanas ampliam-se, ultrapassando o nível das necessidades de sobrevivência e surgindo necessidades propriamente sociais.

Esclareçamos, porém, um pouco mais, o processo de objetivação do ser humano que ocorre na atividade. A forma básica e primeira de atividade humana é a de transformação da natureza. O produto do trabalho é, ao mesmo tempo, a realização de um objetivo previamente existente na mente humana e a transformação da atividade dos sujeitos em propriedades dos objetos:

\footnotetext{
Por isso precisamente é somente na elaboração do mundo objetivo que o homem se afirma realmente como um ser genérico. Essa produção é sua vida genérica ativa. Mediante ela aparece a natureza como sua objetivação da vida genérica do homem, pois este se desdobra não só intelectualmente, como na consciência, mas ativa e realmente, e se contempla a si mesmo num mundo criado por ele. (Marx, 1985, p. 112)
}

Mas, no longo período da história social marcado pela divisão das sociedades em classes antagônicas, as relações de produção existentes entre as classes fundamentais caracterizaram-se pela divisão social do trabalho, acarretando que a objetivação do ser humano e a apropriação dos resultados dessa objetivação ocorressem sob formas que impediram que a totalidade da riqueza material e não material fosse posta a serviço da realização e do desenvolvimento da totalidade dos seres humanos.

Nas sociedades divididas em classes antagônicas, os resultados da produção material realizada pelas classes dominadas beneficiam as classes dominantes. No caso da sociedade capitalista, uma parcela considerável dos produtos da atividade de trabalho é incorporada ao capital, ou seja, a apropriação dos produtos da atividade humana dá-se sob uma forma social que aliena esses produtos da classe que os produz:

\begin{abstract}
A tal ponto aparece a realização do trabalho como desrealização do trabalhador, que este é desrealizado até chegar a morrer de fome. A objetivação aparece a tal ponto como perda do objeto que o trabalhador se vê privado dos objetos mais necessários não somente para a vida, mas inclusive para o trabalho. Mais do que isso, o próprio trabalho converte-se num objeto do qual o trabalhador só pode se apoderar com o maior esforço e com as mais extraordinárias interrupções. A apropriação do objeto aparece em tal medida como alienação, que quanto mais objetos produz o trabalhador, tanto menos consegue possuir e tanto mais submetido fica à dominação de seu produto, quer dizer, do capital. (idem, p. 106)
\end{abstract}

Ocorre que não há outra maneira de o indivíduo humano se formar e se desenvolver como ser genérico senão pela dialética entre a apropriação da atividade humana objetivada no mundo da cultura (aqui entendida como tudo aquilo que o ser humano produz em termos materiais e não materiais) e a objetivação da individualidade por meio da atividade vital, isto é, do trabalho. Na sociedade capitalista, o trabalho produz riqueza objetiva e subjetiva, mas nem uma nem outra podem ser plenamente apropriadas por aqueles que trabalham:

\footnotetext{
A alienação do trabalhador em seu objeto se expressa, segundo as leis econômicas, da seguinte forma: quanto mais o trabalhador produz, tanto menos tem para consumir;
} 
quanto mais valores cria, tanto mais sem valor, tanto mais indigno ele é; quanto mais elaborado é seu produto, tanto mais disforme é o trabalhador; quanto mais civilizado é seu objeto, tanto mais bárbaro é o trabalhador; quanto mais rico espiritualmente se faz o trabalho, tanto mais desespiritualizado e ligado à natureza fica o trabalhador. [...] Certamente o trabalho produz maravilhas para os ricos, porém produz privações para o trabalhador. Produz palácios, porém para o trabalhador produz choupanas. Produz beleza, porém deformidades para o trabalhador. Substitui o trabalho por máquinas, porém lança uma parte dos trabalhadores a um trabalho bárbaro, e converte em máquinas a outra parte. Produz espírito, porém gera estupidez e cretinice para o trabalhador. (idem, p. 107-108)

Para Marx, a superação positiva da propriedade privada, ou seja, a superação da sociedade capitalista, não significaria a abolição do trabalho, nem mesmo o abandono da riqueza material e espiritual produzida pelo trabalho alienado, mas sim a superação dessa forma histórica da atividade humana que é o trabalho alienado pela sua transformação em autoatividade. Isso significa uma mudança de quatro aspectos da atividade humana: a relação do sujeito com os resultados da atividade humana, a relação do sujeito com sua própria atividade, a relação do sujeito consigo mesmo como ser genérico, isto é, representante do gênero humano, e a relação do sujeito com os outros sujeitos.

O produto do trabalho contém a atividade humana nele fixada, ele é a objetivação do trabalho, é a atividade transformada em objeto: "a realização efetiva do trabalho é a sua objetivação" (idem, p. 105). Nesse sentido, o produto do trabalho é a realização efetiva do sujeito, é a transformação da atividade do sujeito em um objeto social. Mas, nas condições em que o trabalho ocorre na sociedade capitalista, o produto do trabalho é uma mercadoria que pertence ao capital, ou seja, "esta realização do trabalho aparece no estádio da Economia Política como desrealização do trabalhador, a objetivação como perda do objeto e servidão a ele, a apropriação como alienação, como exteriorização" (idem, p. 105-106).
Nesse contexto da análise marxiana, a palavra "exteriorização" (Entäusserung) não deve ser confundida com objetivação (Vergegenständlichung). Exteriorização significa, nesse contexto, que o produto do trabalho, ao ser apropriado pelo capital, se torna algo que não expressa a individualidade do trabalhador, mas sim, ao contrário, que se defronta com o trabalhador como um ser hostil e estranho, como um ser alheio ao ser do indivíduo que o produziu. É por isso que nos Manuscritos o conceito de exteriorização se identifica ao de alienação.

A exteriorização do trabalhador em seu produto significa não somente que seu trabalho se converte em um objeto, em uma existência exterior, mas que existe fora dele, independente, estranho, que se converte em um poder independente frente a ele; que a vida que emprestou ao objeto se lhe defronta como coisa estranha e hostil. (idem, p. 106)

A objetivação, que é a única forma de o ser humano se efetivar, se desenvolver, torna-se uma objetivação alienante. Mas isso não significa, de forma alguma, que necessariamente a objetivação produza alienação e exteriorização. As relações sociais capitalistas é que transformam aquilo que seria humanização em seu oposto, ou seja, em alienação: transformam, conforme anteriormente citado, a realização efetiva do trabalho em desefetivação do trabalhador, transformam a objetivação em perda do objeto e servidão ao mesmo, posto que o objeto assume a forma de capital.

$\mathrm{Na}$ sociedade comunista, superadas as relações capitalistas de produção, o mundo resultante da objetivação deixa de ser alheio, inimigo e hostil em relação ao indivíduo e passa a ser a confirmação da sua individualidade:

Assim, ao fazer-se para o homem em sociedade a realidade objetiva realidade das forças humanas essenciais, realidade humana e, por isso, realidade de suas próprias forças essenciais, se fazem para ele todos os objetos objetivação de si mesmo, objetos que afirmam e realizam sua individualidade, objetos seus, isto é, ele mesmo se faz objeto. (idem, p. 149) 
Isto porque na sociedade comunista a forma de apropriação do objeto do trabalho se modifica radicalmente em comparação com a sociedade capitalista, na qual as relações dos seres humanos com o mundo por eles produzido são reduzidas a uma única forma de apropriação, qual seja, ao ter, à posse imediata: "a propriedade privada nos fez tão estúpidos e unilaterais que um objeto só é nosso quando o temos, quando existe para nós como capital ou quando é imediatamente possuído, comido, bebido, vestido, habitado, em resumo, utilizado por nós" (idem, p. 148).

A superação dessa unilateralidade ocorrerá, na sociedade comunista, pela transformação da apropriação em um processo de apropriação omnilateral.

O homem se apropria de sua essência universal de forma universal, quer dizer, como homem total. Cada uma de suas relações humanas com o mundo (ver, ouvir, cheirar, degustar, sentir, pensar, observar, perceber, desejar, agir, amar), em resumo, todos os órgãos de sua individualidade, como os órgãos que são imediatamente comunitários em sua forma são, em seu comportamento objetivo, em seu comportamento perante o objeto, a apropriação deste. A apropriação da realidade humana, seu comportamento diante do objeto, é a afirmação da realidade humana; é, por isso, tão polifacético quanto múltiplas são as determinações essenciais e as atividades do homem, pois o sofrimento, humanamente entendido, é um gozo próprio do homem. (idem, p. 147-148)

Assim, superadas as relações sociais alienadas, mudam radicalmente as relações dos seres humanos tanto com os produtos já existentes na cultura, como com os produtos gerados pela atividade do indivíduo. A objetivação que o indivíduo realiza por meio de sua atividade passa a ser um processo no qual sua individualidade se transforma em objeto social, objeto que realiza o indivíduo e enriquece aos demais seres humanos. Igualmente, a apropriação dos objetos sociais já existentes na cultura forma o indivíduo como um ser humano:

Somente por meio da riqueza objetivamente desenvolvida do ser humano é, em parte cultivada, em parte criada, a riqueza da sensibilidade humana subjetiva, um ouvido musical, um olho para a beleza da forma. Em resumo, somente assim se cultivam ou se criam sentidos capazes de gozos humanos, sentidos que se afirmam como forças essenciais humanas. Pois não apenas os cinco sentidos, mas também os chamados sentidos espirituais, os sentidos práticos (vontade, amor etc.), em uma palavra, o sentido humano, a humanidade dos sentidos, se constituem unicamente mediante a existência de seu objeto, mediante a natureza humanizada. A formação dos cinco sentidos é um trabalho de toda a história universal até nossos dias. (idem, p. 150)

Mas a relação dos indivíduos com os produtos da atividade humana não pode transformar-se radicalmente se não ocorrer a mesma transformação da relação entre o sujeito e sua própria atividade. $\mathrm{O}$ produto do trabalho alienado assume a forma de um objeto alheio, estranho, externo e hostil ao trabalhador. Mas, como afirma Marx: “o produto não é mais que o resumo da atividade, da produção. [...] $\mathrm{Na}$ alienação do produto do trabalho não faz mais que se resumir a alienação, a exteriorização na atividade do próprio trabalho" (idem, p. 108).

Nessas circunstâncias, o que significa para o trabalhador a atividade de trabalho?

Primeiramente, que o trabalho é externo ao trabalhador, quer dizer, não pertence a seu ser; que em seu trabalho não se afirma, mas se nega; não se sente feliz, mas infeliz; não desenvolve uma livre energia física e espiritual, mas mortifica seu corpo e arruína seu espírito. Por isso o trabalhador só se sente em si fora do trabalho, e no trabalho se sente fora de si. Está em sua casa quando não trabalha e quando trabalha não está em sua casa. Seu trabalho não é, assim, voluntário, mas forçado, trabalho forçado. Por isso não é a satisfação de uma necessidade, mas somente um meio para satisfazer as necessidades fora do trabalho. (idem, p. 108-109)

Para que a relação do ser humano com seu trabalho mude radicalmente numa sociedade comunista, é necessário que a atividade deixe de ser um meio para a satisfação de necessidades externas a ela e passe a ser ela mesma um processo no qual o sujeito se 
desenvolve e se realiza como um ser humano. O trabalhador aliena-se de seu trabalho porque é obrigado a vender sua atividade em troca de um salário que lhe assegure a sobrevivência. Isso quer dizer que, para poder continuar a viver, o trabalhador deve vender uma parte de sua vida e, mais do que isso, vender a parte mais importante de sua vida, que é a atividade por meio da qual ele poderia formar-se, fazendo da essência humana, isto é, das potências essenciais humanas formadas historicamente, a essência de sua individualidade.

Mas essa relação de exterioridade não é intrínseca à atividade de trabalho, ela acontece nas condições de alienação. Superar essas condições significa transformar a atividade em autoatividade, ou seja, em atividade autorrealizadora. A atividade vital como atividade autorrealizadora é a única forma de o indivíduo se efetivar como um ser genérico, isto é, um ser conscientemente representativo do desenvolvimento alcançado pelo gênero humano. A superação do trabalho alienado não se dá pela negação do trabalho ou pela busca de uma suposta essência reprimida no interior do indivíduo, mas sim pela transformação da atividade em relação consciente com o mundo resultante da objetivação histórica e social do gênero humano:

Por isso precisamente é somente na elaboração do mundo objetivo que o homem se afirma realmente como um ser genérico. Essa produção é sua vida genérica ativa. Por ela aparece a natureza como sua objetivação da vida genérica do homem, pois este se desdobra não só intelectualmente, na consciência, mas também ativa e realmente, e se contempla a si mesmo num mundo criado por ele. (idem, p. 112)

Se o trabalho é a atividade vital humana, é a atividade pela qual a essência historicamente formada do gênero humano pode transformar-se em riqueza da individualidade, a venda dessa atividade em troca da sobrevivência produz uma cruel inversão:

$\mathrm{Na}$ forma da atividade vital reside o caráter dado de uma espécie, seu caráter genérico, e a atividade livre, consciente, é o caráter genérico do homem. A vida mesma aparece so- mente como meio de vida. [...] A atividade vital consciente distingue imediatamente o homem da atividade vital animal. Justamente, e só por isso, é ele um ser genérico. Ou, dito de outra forma, somente é ser consciente, quer dizer, somente é sua própria vida objeto para ele, porque é um ser genérico. Só por isso sua atividade é livre. O trabalho alienado inverte a relação, de maneira que o homem, precisamente por ser um ser consciente, faz de sua atividade vital, de sua essência, um simples meio para sua existência. (idem, p. 111-112)

Superando-se as relações sociais de produção que tornam o trabalho uma atividade alienada, supera-se também a relação alienada que obriga o indivíduo a fazer da vida genérica apenas um meio para a sobrevivência. Supera-se assim a contradição entre a individualidade e a condição de ser genérico.

Por fim, transforma-se nesse mesmo processo de superação do capitalismo a relação do ser humano com o outro ser humano, que deixa de ser a relação entre o trabalhador - que no ato da venda de sua força de trabalho se aliena da atividade que o formaria plenamente como ser humano e por meio da qual ele participaria conscientemente da formação de um mundo plenamente humano - e o capitalista. $\mathrm{Na}$ sociedade capitalista, a relação do trabalhador com o outro, isto é, o capitalista, não é uma relação que satisfaça uma necessidade do trabalhador como indivíduo, como pessoa, mas sim um meio para sua sobrevivência. Na sociedade comunista, a relação com o outro deixa de ser um meio para satisfação de uma necessidade externa à relação e passa ela mesma a ser uma necessidade das individualidades dos sujeitos que se relacionam. Dessa forma, para o indivíduo, torna-se uma necessidade relacionar-se com o outro indivíduo pelo que nele há de humano. A humanidade do outro torna-se uma necessidade da humanidade de cada um (idem, p. 142-143).

A perspectiva marxiana da sociedade comunista é a de uma sociedade na qual a formação humana produz o homem rico:

O homem rico é, ao mesmo tempo, o homem necessitado de uma totalidade de exteriorização vital humana. O homem no 
qual sua própria realização existe como necessidade interna, como urgência. Não somente a riqueza, também a pobreza do homem, recebe igualmente numa perspectiva socialista um significado humano e, por isso, social. A pobreza é o vínculo passivo que faz sentir ao homem como necessidade a maior riqueza, o outro homem. A dominação em mim do ser objetivo, a exploração sensível de minha atividade essencial, é a paixão que, com isso, se converte aqui na atividade de meu ser. (idem, p. 153-154)

Não seriam, porém, essas palavras escritas na juventude de Marx um resquício do idealismo hegeliano? Não teria Marx, em sua maturidade, ao avançar em seus estudos sobre o modo de produção capitalista, abandonado as preocupações juvenis relativas ao desenvolvimento da individualidade humana? $\mathrm{O}$ trecho a seguir, extraído dos Grundrisse, escritos entre 1857 e 1858, mostra claramente que a resposta a essas perguntas é negativa, ou seja, que Marx não abandonou sua concepção acerca do desenvolvimento livre e universal dos indivíduos:

\begin{abstract}
A limitação do capital é que todo o seu desenvolvimento se efetua de maneira antagônica e que a elaboração das forças produtivas, da riqueza universal, da ciência, etc., aparece como alienação do trabalhador, que se comporta frente às condições produzidas por ele mesmo como frente a uma riqueza alheia e causadora de sua pobreza. Porém, esta forma contraditória é transitória e produz as condições reais de sua própria abolição. O resultado é que o capital tende a criar essa base que contém, de maneira potencial, o desenvolvimento universal das forças produtivas e da riqueza, assim como a universalidade das comunicações, numa palavra, a base do mercado mundial. Esta base contém a possibilidade do desenvolvimento universal do indivíduo. O desenvolvimento real dos indivíduos a partir desta base, pela qual cada barreira é constantemente superada, lhe proporciona esta consciência: nenhum limite pode ser considerado como sagrado. A universalidade do indivíduo já não se realiza no pensamento ou na imaginação; está viva em suas relações teóricas e práticas. (Marx, s.d., vol. 2, p. 31-32)
\end{abstract}

Os aspectos históricos e ontológicos da formação humana unem-se no pensamento de Marx numa perspectiva dialética de criação das condições de humanização a partir das relações sociais alienadas. Superar a alienação para alcançar-se o pleno desenvolvimento da individualidade livre e universal: essa é a perspectiva da sociedade comunista em Marx. E como a filosofia pode contribuir para que a educação se insira nesse processo de construção dessa nova sociedade a partir das condições atuais, marcadas por relações sociais alienadas? Pensamos ser possível sintetizar as contribuições da filosofia recorrendo ao conceito de "clássico" que se reporta ao patrimônio cultural da humanidade que deve ser assimilado pelas novas gerações como elemento de sua plena humanização.

\section{A filosofia da educação e o acesso aos clássicos como condição necessária à formação humana}

O termo "clássico" é utilizado com diferentes acepções. Derivado da palavra "classe", significou inicialmente "de primeira ordem", "de primeira classe". Sua origem estaria na classificação censitária feita pelo rei Sérvio Túlio, que governou Roma entre 578 e 535 a.C. Na divisão da população de Roma em cinco classes de renda, foram considerados clássicos os cidadãos mais ricos, que, por isso, integravam a primeira classe. Mas já no século II d.C. o gramático latino Aulo Gélio passou a designar como "clássico" o escritor que, pela correção da linguagem, se constituía em autor de primeira ordem (classicus scriptor). A partir daí, incorporou-se à noção de "clássico" a ideia de algo que é referência para os demais, que corresponde às regras, que se aproxima da perfeição, que é sóbrio, simples, isento de ornamentações, que é paradigmático, modelar, exemplar. E dessa conceituação derivou o sentido de "clássico" como o que é usado nas escolas, nas aulas, nas classes de ensino.

Vê-se, então, que o termo "clássico" não coincide com o tradicional e também não se opõe ao moderno. Tradicional é o que se refere ao passado, sendo frequentemente associado ao arcaico, a algo ultrapassado, o que leva à rejeição da pedagogia tradicional, reconhecendo-se a validade de algumas das críticas que a Escola Nova formulou a essa pedagogia. Moderno 
deriva da expressão latina modus hodiernus, isto é, "ao modo de hoje". Refere-se, pois, ao momento presente, àquilo que é atual, sendo associado a algo avançado. Em contrapartida, clássico é aquilo que resistiu ao tempo, tendo uma validade que extrapola o momento em que foi formulado. Define-se, pois, pelas noções de permanência e referência. Uma vez que, mesmo nascendo em determinadas conjunturas históricas, capta questões nucleares que dizem respeito à própria identidade do homem como um ser que se desenvolve historicamente, o clássico permanece como referência para as gerações seguintes que se empenham em se apropriar das objetivações humanas produzidas ao longo do tempo.

A filosofia, enquanto concepção de mundo, formula e encaminha a solução dos grandes problemas postos pela época em que ela se constitui. Como tal, ela contém em si, de forma sintética e conceptualizada, a problemática da época. Por isso, os filósofos que a História reconhece como tais são os grandes intelectuais que conseguiram expressar de forma mais elaborada os problemas das respectivas fases de desenvolvimento da humanidade. Nesse sentido, tornaram-se clássicos, isto é, integram o patrimônio cultural da humanidade, já que suas formulações, embora radicadas numa época determinada, extrapolam os limites dessa época, mantendo o seu interesse mesmo para as épocas ulteriores.

No sentido referido, o estudo crítico dos grandes filósofos, isto é, dos clássicos da filosofia, é uma via de acesso privilegiada à compreensão da problemática humana, o que tem grande valor educativo, já que a educação não é outra coisa senão o processo por meio do qual se constitui em cada indivíduo a universalidade própria do gênero humano.

Superando o imediato e o conjuntural e direcionando o processo educativo para os aspectos essenciais e as disposições duradouras, o recurso ao clássico opera, também, como antídoto à polemização do campo pedagógico.

Com efeito, a trajetória histórica da pedagogia traz a marca da polêmica. Especialmente ao longo do século XX, o pensamento pedagógico foi atravessado por tendências contrapostas, a disputar a hegemonia do campo educativo. Pedagogia conservadora versus pedagogia progressista, pedagogia católica (espiritualista) versus pedagogia leiga (materialista), pedagogia autoritária versus pedagogia da autonomia, pedagogia repressiva versus pedagogia libertadora, pedagogia passiva versus pedagogia ativa, pedagogia da essência versus pedagogia da existência, pedagogia bancária versus pedagogia dialógica, pedagogia teórica versus pedagogia prática, pedagogias do ensino versus pedagogias da aprendizagem e, dominando todo o panorama e, em certo sentido, englobando as demais oposições, pedagogia tradicional versus pedagogia nova.

Buscando tornar coesos os respectivos integrantes, cada um dos grupos em litígio elaborava o próprio discurso enfatizando as diferenças e destacando os pontos que o separavam do oponente, elegendo os slogans que melhor tipificavam cada posição e que possuíam maior poder de atração para agregar novos aderentes.

Ora, como mostram os estudos da filosofia analítica da educação, os slogans não coincidem com as definições. Enquanto estas são consideradas esclarecedoras, aqueles são estimulantes, tendo por função unificar as ideias e atitudes dos movimentos educacionais.

Podemos ilustrar essa distinção com o enunciado "ensinamos crianças, não matérias", objeto de grande difusão pelo movimento da Escola Nova. O que queremos dizer com essa expressão? Do ponto de vista gramatical ela não se sustenta, uma vez que o verbo ensinar é bitransitivo, comportando, pois, tanto o objeto direto como o indireto. Na verdade, não é possível, gramaticalmente, dizer que se ensina nada a alguém, nem que se ensina algo a ninguém. De fato, a ação de ensinar implica que algo seja ensinado a alguém. Portanto, deveríamos dizer que "ensinamos matérias às crianças", não fazendo sentido a afirmação de que "ensinamos crianças, não matérias", do mesmo modo que seria sem sentido afirmar que "ensinamos matérias, não crianças”. Então, qual é a razão do enunciado? Ora, ele justifica-se exatamente na medida em que 
não se trata de uma definição, mas de um slogan. E, enquanto slogan, tem o caráter de um símbolo aglutinador de adeptos em torno da ideia da centralidade da criança no processo educativo. Em outros termos: partindo da consideração de que as atenções dos educadores haviam se voltado excessivamente para as matérias, para o conteúdo da aprendizagem, deixando em segundo plano as crianças, que são, ao fim e ao cabo, a razão de ser do processo educativo, cunhou-se o lema "ensinamos crianças, e não matérias". Pretendia-se, com esse lema, alertar os professores para o fato de que sua preocupação principal deve girar em torno dos educandos, a partir de cujos interesses o currículo e, portanto, o conteúdo, deve ser organizado.

Impõe-se, pois, a conclusão: "ensinamos crianças, não matérias" é um slogan que a Escola Nova lançou contra a Escola Tradicional. Considerando que, com a predominância da Escola Tradicional, a vara foi entortada para o lado das matérias, a Escola Nova, exercitando a "teoria da curvatura da vara", buscou curvar a vara para o lado da criança. Nesse movimento, o slogan passou a ser defendido como se fosse afirmação literal. Assim, o enunciado "ensinamos crianças, não matérias" difundiu-se como se fosse a pura expressão de uma verdade pedagógica.

Podemos, pois, concluir que a Escola Nova tem se utilizado amplamente da "teoria da curvatura da vara", considerando-a, diferentemente do uso feito no livro Escola e democracia (Saviani, 2009), como um dispositivo instaurador da própria verdade. Com efeito, nesse livro em nenhum momento se deixa pairar no ar a suspeita de que se tivesse a pretensão de enunciar alguma verdade ao se enunciar a "teoria da curvatura da vara". Ao contrário, declara-se em alto e bom som, deixa-se explícito com todas as letras que se estava curvando a vara para o outro lado; que se estava invertendo o modo corrente de pensar. E que, se a posição correta não estava do lado da Escola Nova, também não estava do lado da Escola Tradicional (Saviani, 2008b, p. 143-147).

Essas considerações recomendam que sejamos cautelosos no julgamento das correntes pedagógicas. Não cabe, pois, aderir a elas ou rejeitá-las em função dos slogans por meio dos quais se deu ou se vem dando a sua divulgação.

Gramsci, em suas notas do cárcere, redigidas em 1932, coincidentemente no mesmo ano em que era lançado no Brasil o "Manifesto dos Pioneiros da Educação Nova", registrou agudas observações, concluindo com o seguinte comentário:

\begin{abstract}
Ainda se está na fase romântica da escola ativa, na qual os elementos da luta contra a escola mecânica e jesuítica se dilataram morbidamente por causa do contraste e da polêmica: é necessário entrar na fase "clássica", racional, encontrando nos fins a atingir a fonte natural para elaborar os métodos e as formas. (Gramsci, 1975, v. III, p. 1.537; na edição brasileira, 1968, p. 124)
\end{abstract}

Pensamos ser válida essa diretriz para o adequado encaminhamento do processo de formação humana. Em lugar de nos perdermos na disputa para saber quem está mais alinhado com as últimas novidades, cabe aceitar o convite para entrar na fase clássica, que é aquela em que já se deu uma depuração, ocorrendo a superação dos elementos da conjuntura polêmica com a recuperação daquilo que tem caráter permanente porque resistiu aos embates do tempo.

Por esse caminho a pedagogia ganha condições de assumir a perspectiva ontológica, apreendendo a educação, isto é, o processo de formação humana, como o contínuo movimento de apropriação das objetivações humanas produzidas ao longo da história. Eis como a filosofia estará concorrendo, na educação, para, a partir das relações alienadas, abolir os entraves que a forma social capitalista vem impondo ao desenvolvimento plenamente livre e universal do ser humano e de sua formação.

\section{Referências bibliográficas}

GRAMSCI, Antonio. Os intelectuais e a organização da cultura. Rio de Janeiro: Civilização Brasileira, 1968.

. Quaderni del cárcere. Edizione critica dell'Istituto Gramsci, a cura di Valentino Gerratana. Torino: Einaudi, 1975. 4 v. Concepção dialética da história. 2. ed. Rio de Janeiro: Civilização Brasileira, 1978. 
MARX, Karl. Teses sobre Feuerbach. In: MARX, Karl; ENGELS, Friedrich. Textos filosóficos. Lisboa: Presença, [s.d.].

MARX, Carlos. Los fundamentos de la crítica de la economia política. Madrid: Alberto Corazón Editor (Comunicación), s/d. 2 v. . Manuscritos: economía y filosofía. Madrid: Alianza Editorial, 1985.

SAVIANI, Dermeval. Educação brasileira: estrutura e sistema. 10. ed. Campinas: Autores Associados, 2008a.

Escola e democracia. 41. ed. Campinas: Autores Associados, 2009.

A pedagogia no Brasil: história e teoria. Campinas: Autores Associados, 2008b.

DERMEVAL SAVIANI, professor emérito da Universidade Estadual de Campinas (UNICAMP), pesquisador emérito do Conselho Nacional de Desenvolvimento Científico e Tecnológico (CNPq) e coordenador geral do Grupo Nacional de Estudos e Pesquisas "História, Sociedade e Educação no Brasil (HISTEDBR). Atua nas áreas de teorias da educação, história da educação, política educacional, formação docente. Publicações recentes: Escola e democracia (Campinas: Autores Associados, 2008. Ed. especial comemorativa dos 25 anos de lançamento e da 40. ed.); História das ideias pedagógicas no Brasil (Campinas: Autores Associados, 2007); A pedagogia no Brasil: história e teoria (Campinas: Autores Associados, 2008); PDE - Plano de Desenvolvimento da Educação: análise crítica da política do MEC (Campinas: Autores Associados, 2009).E-mail: dermevalsaviani@yahoo.com.br

NEWTON DUARTE, doutor em educação pela UNICAMP, professor titular do Departamento de Psicologia da Educação da Faculdade de Ciências e Letras da Universidade Estadual Paulista (UNESP), campus de Araraquara, autor, entre outros trabalhos, dos livros $A$ individualidade para-si (Campinas: Autores Associados, 1993); Vigotski e o aprender a aprender (Campinas: Autores Associados, 2000); Sociedade do conhecimento ou sociedade das ilusões? (Campinas: Autores Associados, 2003). E-mail: newton. duarte@uol.com.br 


\section{Resumos/Abstracts/Resumens}

Dermeval Savini e Newton Duarte

A formação humana na perspectiva
histórico-ontológica
O tema da formação humana está no
centro da filosofia da educação, cujo
objeto é precisamente o processo de
promoção humana levado a efeito
pela educação. A partir da vigilância
crítica, própria da filosofia, o texto
esboça uma fenomenologia da época
atual, constatando que as ideias
atualmente hegemônicas na educação
se centram na crítica à razão e às
noções de verdade e de objetividade.
A esse neopragmatismo que, na
tentativa de opor-se à metafísica,
acaba por ser profundamente
metafísico reduzindo tudo à
linguagem, os autores contrapõem
o pensamento de Marx como uma
filosofia historicizadora em que estão
em causa não os sujeitos abstratos,
mas os indivíduos reais, sujeitos
históricos que se constituem como
síntese de relações sociais. Para
tanto, recorre-se à reflexão histórico-

ontológica sobre a formação humana contida nos Manuscritos econômicofilosóficos de 1844, de Marx. O artigo conclui com a defesa da tese de que o acesso aos clássicos é condição necessária para a formação humana. Palavras-chave: formação humana; filosofia da educação; marxismo

\section{Human formation in the historical} ontological perspective

The theme of human formation is at the centre of the philosophy of education, whose aim is precisely the process of human promotion brought about by education. Starting from the critical vigilance proper to philosophy, the text sketches a phenomenology of the present time, verifying that the ideas prevailing in education at present are centred on the critique of reason and on the notions of truth and objectivity. This neo-pragmatism, which in the attempt to oppose metaphysics becomes deeply metaphysical, reducing everything to language, is contested by the authors with Marx's thoughts as a historicising philosophy that concerns not abstract subjects, but real individuals, historical subjects that are constituted as a synthesis of social relations. To that end, the authors resort to the historical ontological reflection on human formation contained in Marx's Economic and Philosophical Manuscripts of 1844. The article concludes by defending the proposition that access to the classics is a necessary condition for human formation.

Key words: human formation; philosophy of education; Marxism

\section{La formación humana en la} perspectiva histórica ontológica El tema de la formación humana está en el centro de la filosofía de la educación cuyo objetivo es precisamente el proceso de promoción humana, llevado a cabo por la educación. Partiendo de la vigilancia crítica, propia de la filosofía, el texto esboza una fenomenología de 
la época actual comprobando que las ideas actualmente hegemónicas en la educación, son centradas en la crítica a la razón y a las nociones de la verdad y de la objetividad. A ese neo pragmatismo que con la intención de oponerse a la metafísica acaba siendo profundamente metafísico reduciendo todo al lenguaje, los autores contraponen el pensamiento de Marx como una filosofía de historicismo en que la causa no son los sujetos abstractos, sino los individuos reales, sujetos históricos que se constituyen como sintesis de relaciones sociales. Para esto se recurre a la reflexión histórica ontológica sobre la formación humana incluida en los "Manuscritos Económico Filosóficos de 1844" de Marx. El artículo concluye con la defensa de la tesis de que el acceso a los clásicos es condición necesaria para la formación humana.

Palabras clave: formación humana; filosofía de la educación; marxismo 